\title{
Artigo \\ Desentendimentos entre parentes: variações da intimidade
}

\author{
Graziele Dainese \\ Universidade Federal do Rio de Janeiro
}

\begin{abstract}
RESUMO: Entre os moradores da Terceira Margem (comunidade localizada no estado de Minas Gerais), a possibilidade dos desentendimentos emergirem faz com que se expresse e valorize um saber concernente ao relacionar. Nesse sentido, se destaca a valorização de uma autodisciplina, marcada pela contenção de atitudes e comportamentos e pela modulação constante entre proximidade e distância no contato uns com os outros. Neste texto, apresento como as tensões explícitas e implícitas são vivenciadas nesse contexto de pesquisa, tendo em vista o diálogo com uma perspectiva de análise cujo pressuposto é abordar os conflitos nas tramas que lhes são constitutivas, atentando para os efeitos relacionais criados por esses acontecimentos. A atenção à maneira como o conflito é vivido entre os moradores da Terceira Margem destaca uma dinâmica relacional, que não é necessariamente exclusiva a um contexto e/ou situação, pois seus princípios e processos estão relacionados tanto às instabilidades quanto às estabilidades da existência.
\end{abstract}

PALAVRAS-CHAVE: Conflito, política, subjetivação, diferenciação.

Para os moradores da comunidade rural Terceira Margem, assim como é certo que na política, o parentesco acaba ${ }^{1}$, pode-se dizer que se há parentesco, há desentendimento. Ainda que a existência de cada pessoa seja significada pela proximidade, desentendimentos são tão comuns quanto próprios às relações entre os mais íntimos. Situada na região do Alto Paranaíba, no estado de Minas Gerais, Terceira Margem é uma das vinte localidades rurais que circunscrevem o diminuto núcleo urbano de Santa Abadia do Pradinho. Embora tenha me 
relacionado tanto com os moradores da cidade quanto com os moradores das localidades, foi a convivência com os margeenses que me permitiu conhecer acontecimentos particulares às relações entre pessoas próximas, tal como aqueles nomeados como desentendimentos. ${ }^{2}$ Durante os nove meses de trabalho de campo, ouvi constantes referências sobre como a qualidade gregária da vida vivida não obscurecia as brigas, discussões, momentos de agressões abertas e o desconforto advindo das tensões mais ou menos explícitas. ${ }^{3}$

No que concerne particularmente aos moradores da Terceira Margem, a união da qual se orgulham é sugerida pelas festas religiosas que atraem diversas pessoas ao local, no cotidiano das trocas entre vizinhos. No entanto, união e harmonia têm como pressuposto diversas possibilidades para a irrupção de dissensões: uma vizinha que passa e não responde ao "bom dia", uma carona que é recusada pelo dono do carro, um parente que se exime do auxílio quando este é necessário, isto sem falar das fofocas que acirram tensões e irrompem desacordos; e da política, que de tempos em tempos, agita os ânimos, aproximando quem é distante, distanciando quem é próximo.

Mas apesar de serem inevitáveis, desentendimentos devem ser evitados. Tal argumento traduz, genericamente, o interesse margeense por esses conflitos. Esses são acontecimentos que mobilizam as pessoas: buscar as causas e origem dos desacordos, evitar acirramentos das tensões implícitas e explícitas ou procurar viver uma vida que não seja marcada por essas experiências são questões prementes aos moradores dessa localidade. São acontecimentos que motivam o interesse a ponto de constituir um saber específico à vivência dessas situações; um saber que se apreende através de um conjunto de práticas, as quais têm como princípio a gestão das tensões mais ou menos explícitas, visando, sua contenção.

Essa contenção é sugerida pela noção de controle: noção ampla o suficiente para traduzir cuidados relativos às relações entre uns e outros e às relações consigo mesmo. No que tange às relações com os outros, destacam-se como aspectos significativos do controle a preocupação em saber lidar com as situações mais potentes de desacordos (o descontrole), em mapear as tensões que o desentendimento em questão acirrou e/ou criou, assim como as agências que possivelmente foram a causa dessa irrupção. No que concerne à outra dimensão do controle, da relação consigo mesmo enquanto princípio de contenção, se afirma a autodisciplina, recomendável aos comportamentos e atitudes, a qual tem como finalidade gerir disposições e tendências subjetivas propícias ao acirramento das contendas. 
As práticas e reflexões que derivam dos desentendimentos permitem descrevê-los como "objetos de preocupação moral" dos moradores da Terceira Margem, à maneira como Foucault $(1984 ; 1985)$ apresenta o interesse grego pelas atividades e usos concernentes aos prazeres sexuais. A menção à elaboração foucaultiana sobre o caso grego importa aqui, à medida que percebo na dedicação margeense aos desacordos cotidianos um "cuidado ético", o qual se explicita nas considerações que frequentemente fazem sobre o saber conviver. Estas considerações se apreendem nas fofocas que disseminam os desentendimentos pelas comunidades, nas conversas ao pé do fogão (que tratam com parcimônia um conflito protagonizado por pessoas queridas) ou nas reflexões que tecem quando relatam sua própria história. A apresentação desses relatos e de situações ouvidas por mim durante o tempo em que estive nessa localidade visa traduzir a atenção que os margeenses dedicam aos conflitos vividos. Entendo que o interesse por esses acontecimentos expressa sua importância na tessitura da vida coletiva. Desentendimentos tornam-se interessantes à análise, à medida que são experiências importantes à maneira como esse coletivo cria sua própria existência. Sendo assim, ao descrever sua dinâmica, tendo como foco o controle (essa prática de si que é inerentemente uma prática social), tenho como interesse apresentar princípios, tendências e disposições que participam do relacionar.

Sob o foco das "problematizações" específicas a essa vivência dos conflitos, nesta descrição estou menos preocupada em classificar comportamentos e ideias que em abordar as práticas que criam e significam. Nesse sentido, este artigo partilha do horizonte teórico comum a trabalhos realizados em outras regiões do Brasil, no que tange à abordagem sobre o funcionamento de diversas situações de conflito. Marques (2002), Comerford (2003) e Figurelli (2011) retratam em seus trabalhos situações bastante diversas entre si, mas semelhantes em relação à maneira como o conflito é abordado. Partindo dessas perspectivas, entendo que antes de traduzir disposições, tendências e acontecimentos que põem em curso apenas rupturas e desestabilizações, as situações conflituosas também são potentes em afirmar e estabelecer novos vínculos, explicitando, assim, princípios que participam da configuração das coletividades. Essas abordagens sobre os desacordos não se preocupam em classificá-los como conflitos abertos, explícitos e/ou implícitos, mas sim em abordá-lo nas tramas que lhes são constitutivas, bem como descrever os efeitos relacionais criados por esses acontecimentos.

O estudo dos desentendimentos parte do pressuposto de que os conflitos vividos na Terceira Margem explicitam uma "arte da existência" (Foucault, 1984) composta por 
práticas coletivas e práticas de si que são criadoras de modos de relação. Seguindo essa sugestão, o presente artigo tem como objetivo apresentar situações que mobilizam um saber viver cultivado nas relações consigo mesmo e com os outros. Em um contexto no qual as tensões dão o tom da convivência entre os mais íntimos, esse conhecimento nos fala de distanciamentos, contenções e das evitações necessárias na gestão das contendas, mas também indica como esses intervalos, criados nas perturbações do convívio, são potentes em (re)criar aproximações. Sendo assim, as descrições aqui apresentadas mapeiam acontecimentos nos quais os distanciamentos e outras variações semelhantes traduzem não apenas uma economia da evitação, posto que os desentendimentos, além de explicitar intervalos que devem ser geridos, não deixam de afirmar outras medidas do relacionar.

\section{Desentendendo}

Entre os margeenses, certos acontecimentos se condensam de modo a formar um cadinho de incompreensões e desencontros que pode se precipitar em desacordos. Não faltam exemplos para esses acontecimentos: a pressa em retribuir o auxílio recebido dias antes ou, ao contrário, a demora em responder ao pedido de ajuda; a frequência excessiva a uma casa, ou a ausência em situações nas quais é premente se fazer presente. As conversas, frequentemente prazenteiras, também podem tomar o rumo de assuntos dos quais se reconhece a inadequação em determinados contextos.

Nesse sentido, as motivações para o desentendimento se assemelham às irrupções de conflito na Zona da Mata Mineira, tal como observou Comerford (2003) para as situações nas quais o desrespeito às divisas frutifica em contenda. Nessas dinâmicas conflitivas, as divisas não são apenas territoriais, mas também existenciais. Desse modo, as cercas que definem um pedaço de terra, o quintal e/ou a soleira da porta de casa (assim como outras referências importantes da domesticidade, a exemplo da cozinha), as pessoas mais íntimas, a presença física em determinados espaços são marcos semelhantes no que tange às delimitações a serem respeitadas. Sendo assim, a indiferença marcada pela falta de um "bom dia" em determinados encontros e a transposição das cercas que delimitam uma propriedade podem ter o mesmo impacto sobre a convivência. Os atos que motivam essas dissensões referem-se ao não reconhecimento da presença do outro e de tudo o que pode identificar essa presença. 
Nessas situações, o outro é sempre alguém íntimo e próximo. Essa intimidade, por sua vez, encontra nas relações de família e parentesco seus principais modelos relacionais. É preciso considerar que os termos parente e família, embora referidos especialmente aos consanguíneos e afins, também podem recobrir outras relações. Aqui são todos conbecidos, aqui são todos parentes é a expressão ouvida quando se caracteriza a Terceira Margem e seu efeito não se limita à retórica, à medida que há um investimento dos moradores em fazer com que a intimidade não se limite aos pressupostos do sangue e do casamento. Desses investimentos, destaco práticas sociais baseadas no trânsito de pessoas (e também de bens, palavras e forças) como modos de efetuação dessas relações.

Essa dinâmica da circulação indica que se tornar conhecido e até mesmo parente é uma condição em aberto, criada pelo exercício dos movimentos, particularmente daqueles que encontram seus termos nas visitas e ajudas. Através dessas práticas que conduzem as pessoas às casas dos moradores da Terceira Margem, os encontros domésticos ganham particularidade frente a tantos outros contatos que os moradores estabelecem com o mundo. Pois há encontros diversos nesse contexto, sejam vividos com aqueles que ali chegam "de fora", durante o tempo da política, ou com quem se troca apenas olhares rápidos pelas ruas da cidade, conversas mais espaçadas com os técnicos da Empresa de Assistência Técnica e Extensão Rural (Emater) e nas andanças pelo mundo a fora. Quando o fluxo de pessoas se estabiliza nas casas, principalmente nas cozinhas, é que há possibilidade do estrangeiro se transformar em conhecido e do conhecido se tornar como se fosse parente. Desse modo, no passo das visitas e outras andanças, percebe-se não apenas quem chega, mas também aquele que nunca se apresenta, sendo a ausência uma afirmação das familiaridades pouco consistentes ou afetadas por outras instabilidades. ${ }^{4}$

Associada aos movimentos que aproximam pessoas e qualificam relações, a intimidade margeense pressupõe que a indiferença pode ser motivo para desentendimentos. Como foi dito anteriormente, nessas situações o outro é próximo, sendo assim, pode-se dizer que as causas dos conflitos estão associadas ao desrespeito às demarcações importantes da intimidade. Em síntese, desentendimentos refletem variações, criadas a partir da violação de limites moralmente definidos. Esse desrespeito se fundamenta numa proximidade ou distanciamento excessivo e frequentemente incentiva a reação, caracterizada por mais distanciamento ou pela aproximação acintosa. Um morador, que sempre se fez presente, deixa de frequentar a casa de um vizinho. A mãe de família, sempre solícita em receber uma conhecida, passa a não dar a devida atenção quando esta se faz presente (pouco conversa, não a convida mais para fazer pamonhas ou preparar a carne de 
porco). Um primo que passa em frente à casa e não cumprimenta, logo ele que nunca negou um "bom dia" à alguém. Ou alguém, mais descontrolado, que resolve chamar na conversa não se contentando em afirmar a dissensão na distância, optando por explicitá-la em enfrentamentos mais diretos.

Essas variações da intimidade também podem estar associadas ao humor de cada um, exceto, claro, as situações de enfrentamento, nas quais a mudança brusca concede pouca margem à especulação. Nessas situações, o desrespeito ao outro se afirma de modo mais inflexível, principalmente quando se torna explícito a um público mais amplo: deriva em provocação. As provocaçoes referem-se aos desafios que implicam respostas, posicionamento frente a uma ofensa que se explicitou publicamente (Comerford, 2003). São acontecimentos comuns ao cotidiano, porém as especificidades de certos contextos lhe dão lastro, e assim, afirmam sua recorrência. ${ }^{5}$

$\mathrm{Na}$ política, essa recorrência ganha notoriedade à medida que este é um contexto propício tanto ao posicionamento quanto às violações. As campanhas eleitorais municipais criam uma variação tão significativa às relações a ponto de um morador reconhecer que na política, o parentesco acaba. Tal variação é efeito do partidarismo, que, nesse contexto, traduz não apenas a orientação para votos, mas especialmente um princípio divisor, atualizado pela política. ${ }^{6}$ A lógica partidária local impõe posicionamentos, que por sua vez, não implicam apenas votos, mas demandam outras formas de participação. Estourar rojões, ouvir jingles, portar bandeiras do candidato, essas e outras são maneiras de expor publicamente seu posicionamento, manifestações necessárias a um momento no qual a neutralidade tem pouco crédito.

Se por um lado essas formas de participação qualificam um momento, por outro, delas derivam a atualização e a criação de tensões. Dessa deriva, as provocações se destacam, pois remetem às situações nas quais as manifestações rompem o fio tênue que distingue a participação do combate. Estourar rojões é bom quando se faz próximo a casa do vizinho, do mesmo modo que ouvir jingles é interessante se os antagonistas possam ouvir também (e em alto e bom som) e quando as coisas assim acontecem o esperado é que o vizinho antagonista se manifeste por meio de atos semelhantes. O que pode resultar desse intercurso não é apenas desentendimento, mas também suas atualizações mais potentes, definidas pela briga e morte, criações de um estado de coisas que se nomeia como descontrole. ${ }^{7}$

Embora a política seja exemplar no que concerne à irrupção dos desentendimentos, é fato que seu acontecimento é da ordem do extraordinário, tanto que circunscreve um “tempo" (Palmeira e Heredia, 1995). Quando relacionamos a política à dinâmica mais geral 
da vida em comum, esta se destaca como atividade catalisadora, atuando como um diapasão das forças, agências e práticas que estão presentes no cotidiano. ${ }^{8}$ Por outro lado, a despeito das criações específicas postuladas pela sazonalidade da política, sua circunscrição a um tempo sugere um aspecto que é significativo não apenas à especificidade da política vivida nesses lugares, mas sobretudo, é significativo à especificidade do desentendimento.

Pode-se entender a própria circunscrição como parte de um conjunto de reflexões e práticas referentes a um saber relacionar, o qual supõe um cuidado nas relações de uns com os outros, cuidado este caracterizado por comportamentos e atitudes a serem observados, principalmente (mas não exclusivamente) em contextos de dissensão. ${ }^{9}$ Esse saber relacionar baseia-se numa reflexão sobre a composição e as disposições das pessoas e sobre tendências específicas às relações entre próximos (parentes e conhecidos), a qual está estreitamente associada a determinados procedimentos e práticas cotidianas.

No que tange à dinâmica dos desentendimentos, tais procedimentos podem ser traduzidos genericamente pelas expressões ter controle, ser controlado. As relações com os outros e consigo mesmo sugerem uma economia da contenção e da evitação. Embora não seja a única, essa é uma tradução possível para a expressão ter controle. Partindo dessas reflexões, podemos entender o ter controle como uma "arte da existência" (Foucault, 1984), composta por práticas coletivas e práticas de si que têm como princípio a gestão de tensões mais ou menos explícitas.

\section{Ter controle}

A relação entre próximos é o que qualifica a existência de cada um: a vida não tem muito sentido quando se faz longe da família, dos parentes, dos conhecidos. Família unida e comunidade unida são valores importantes, referências para as conversas que tratam sobre as expectativas da vida. Situações nas quais a ausência das pessoas queridas se tornou imperativas (e nessas situações, a distância pode ser traduzida pelos deslocamentos motivados pela busca de emprego e melhorias na condição de vida, por viagens mais temporárias) são descritas sob o tom do dissabor e do lamento. Não sou ninguém longe do meu povo, é referência constante para esses momentos em que a separação dá o tom da relação que antes era mais estreita.

Separações, distanciamentos e ausências também são mencionados quando se fala sobre os dissabores da dissensão. As consequências dos desentendimentos são reconhecidas 
pelo infortúnio que trazem às pessoas, a exemplo do sofrimento que pode acometer aqueles que se distanciam por conta das tensões irrompidas. Tendo em vista essas consequências, a afirmação da existência dos desentendimentos não prescinde da recomendação de que o melhor é quando se pode evita-los ou dirimi-los. É esse entendimento que fundamenta a contenção implícita no conselho: bom mesmo é ter controle.

Enquanto princípio de contenção, o controle supõe uma autodisciplina, a qual tem como finalidade gerir disposições e tendências subjetivas propícias às contendas. As formas de exteriorização da pessoa (seus comportamentos e atitudes) refletem aspectos internos, definidos como lado bom e lado não tão bom. Da definição margeense de pessoa apreende-se a existência dos lados e dos ânimos que os manifestam. Por vezes, os margeenses diziam que o lado bom e o lado não tão bom se confundem com esses ânimos. Mas sobre isso não há um consenso, pois também se considera a distinção entre afetos e lados da pessoa: desse ponto de vista, cada lado corresponde a uma gama de afetos específicos. No que tange ao lado bom referem-se à boa vontade como um denominador comum dos ânimos associados às condutas da proximidade benfazeja: uma disposição à sempre ajudar, a cultivar as conversas das visitas. Por sua vez, do lado não tão bom, a paixão é o denominador para uma série de afetos como a inveja, a ambição, o ciúmes.

Os ânimos que remetem à paixão são responsáveis pela manifestação do lado não tão bom, de modo que sua existência participa dos comportamentos e atitudes que motivam desentendimentos. Ao tratar da maneira como as pessoas incitam umas as outras às contendas, os margeenses se referem a esse afeto: fulano vive nessa toada de ir às casas para falar dos outros, vai falar pra modo de caşar desentendimento. Isso ai é da paixão, disse-me uma moradora ao caracterizar os efeitos das conversas que tomam o rumo das fofocas. Dado a peculiaridade desses efeitos (caçar desentendimento), é frequente a associação da paixão a uma qualidade coletiva: tal como se diz da maldade do povo.

A paixão que se manifesta nas campanhas eleitorais municipais e a paixão que se expressa no dia-a-dia se assemelham na maneira como influenciam a vida pessoal e coletiva. A paixão adjetiva a política e nos apresenta uma dimensão do fenômeno que não se refere à atividade, mas sim à subjetivação: nas campanhas eleitorais o que se observa são transformações de comportamentos, que embora possam ser criticadas, não deixam de ser adequadas ao momento. Ficar louco ou fanático são condições muito comuns nesse período, e até o sujeito mais tranquilo pode sucumbir ao ensejo das manifestações partidárias apaixonadas. Credita-se à paixão o fato das provocações serem mais contínuas e intensas nesse período. 
Para além do contexto das campanhas eleitorais, o termo política deixa de ser sinônimo de paixão e esta se especifica em outros nomes: inveja, ciúmes e ambição. Embora mude de nome, sua manifestação no mundo é similar ao que se observa nos contextos políticos, pois refletem a alteração de comportamentos e atitudes individuais e tem efeito sobre a vida coletiva: dotados de agência, eles fazem fazer coisas (Latour, 2002), motivando provocaçoes, desentendimentos. Das brigas entre primas, explica-se que foi consequência da inveja de alguém que, ao dar ensejo à fofoca, acabou por afastá-las; sobre as oscilações materiais que marcam a vida de alguém, estas podem ser atribuídas à ambição de outra pessoa, que o prejudicou em algum negócio.

Reconhece-se que, sendo as pessoas compostas por paixões, é esperado que em algum momento tais afetos sejam expressados. No entanto, essa possibilidade não anula o reconhecimento da necessidade de administrar as manifestações, de que é preciso ter controle. O que a existência desses afetos pressupõe é menos uma dimensão natural do humano e mais uma maneira de ser que deve ser cultivada. Ter controle se afirma como um modo de subjetivação aprendido ao longo da vida, o qual se caracteriza por exercícios de contenção dessas manifestações. Desses exercícios se destacam a rez̧a e o sofrimento.

Enquanto modalidade de proteção divina, a rę̧a também se afirma como possibilidade de evitar a ação de forças que são ocultas, mas que não são estranhas às pessoas. ${ }^{10}$ Tentação, inveja, ambição essas e outras paixões podem ser controladas por rezas: formas de proteção, mas também orientação de condutas, posto que confrontadas à leitura dos exemplos bíblicos é possível aprender modos de se comportar frente aos outros e em relação consigo mesmo. A bíblia oferece os arquétipos da solidariedade, do comportamento ordeiro e devoto, das atitudes que cultivam a harmonia na vida em comum.

Desse texto, também se apreende a experiência transformadora do sofrimento: vivenciado por diversos pecadores que após a morte se tornaram santos. O sofrimento experimentado pelos moradores da Terceira Margem, embora nem sempre se traduza em experiência sagrada, tampouco deixa de ser experiência transformadora. Relatos de pessoas que viviam às turras com parentes e conhecidos e que mudaram de atitude frente à vida após vivências significativas de sofrimento são constantes entre os margeenses e atestam a capacidade que cada um tem de transformar a si mesmo.

As vivências do sofrimento frequentemente são caracterizadas por rupturas e distanciamentos familiares que podem ser criadas por dissensões, mas também por outros fatores, sendo as mortes (naturais ou como efeito do desentendimento: suicídio, morrer de 
desgosto...) um dos mais mencionados: um filho que se afasta do pai e tal afastamento tem efeito transformador sobre um dos dois; a morte de alguém muito próximo que faz com que o outro possa ressignificar sua conduta frente ao padecimento dessa ausência; a separação entre marido e mulher e o decorrente afastamento dos filhos.

Os efeitos da transformação criada pelo sofrimento são observados nas relações entre uns e outros: comportamentos associados às práticas de solidariedade e proximidade (visita, ajuda) e à evitação das disputas e desentendimentos atestam uma subjetividade menos refém dos seus próprios afetos. Este efeito sugere que o controle, enquanto prática de si pressupõe uma intensificação das relações sociais, no sentido de que a eficácia esperada é preservar as relações com os outros a partir da administração dos efeitos das manifestações das paixões sobre si mesmo. Essa intensificação das relações sociais se observa nessa disposição em preservar as relações vividas na comunidade - cuidar de si não deixa de ser uma forma de cuidar de suas próprias relações. Nesse sentido, o controle é prática social não apenas porque o efeito das paixões é observado na vida coletiva, mas também porque a relação com os outros dá a matéria para a administração de si mesmo. Através dessas relações é possível exercitar outros ânimos e outros aspectos de si, assim como controlar as paixões. Se por um lado as relações entre parentes e conhecidos são aquelas que mais padecem com a manifestação das paixões, por outro são elas que inspiram modelos de conduta consigo mesmo - dada a importância da proximidade e da harmonia na convivência com as pessoas este é o mote para cultivar uma relação diferente com seus próprios ânimos (controlando-os).

\section{Desentender e conviver}

O controle também orienta procedimentos mais diretamente acionados nas relações de uns com os outros. Quando Alzira deixou de frequentar a casa de sua irmã Liduína, após uma pequena discussão sobre a forma como deveriam fazer biscoitos, Liduína pediu ao neto que levasse um queijo à Alzira: essa forma de aproximação, além de permitir saber qual o motivo que afastou a irmã de sua casa, também permitia a Liduína sinalizar à Alzira uma tentativa em reverter o constrangimento criado pela pequena discussão, de modo a não transformá-lo em tensões mais perenes.

Outras situações são igualmente loquazes em termos de cuidado e precaução e não faltam exemplos de iniciativas que, embora possam prejudicar a pessoa, ainda assim são observadas, a fim de não entrar em conflito. Apesar de muitos dos habitantes da localidade Terceira Margem serem donos de suas casas, nenhum deles tem um documento formal 
atestando a posse. Dizem que as negociações foram feitas no boca-a-boca entre os vizinhos e que muitas demarcações do território da moradia foram refeitas após essas negociações, sendo muito comum as situações nas quais se incluiu como parte de sua posse um pedaço da terra que pertencia a outro. As casas situadas mais próximas à capela são as mais citadas para esses casos, dado o fato de que comumente seus moradores tomaram parte das terras entorno da capela para plantar café ou outro cultivo. No ano de 2009, a prefeitura decidiu demarcar formalmente esses lotes, avisando aos moradores de que deveriam se encaminhar até um secretário municipal, a fim de indicar os limites de suas posses. No entanto, nenhum morador teve interesse em fazê-lo e ninguém encaminhou qualquer informação ao órgão público. Alguns explicavam o desinteresse pelo fato de que até então tudo tinha dado certo da forma como sempre foi e que não havia necessidade de modificar a situação. Por outro lado, também não desconsideravam o fato de que, apesar de ser vantajoso terem um documento atestando a propriedade, desentendimentos podiam surgir quando fossem medidas as posses de cada um e tivessem que afirmar peremptoriamente as demarcações que renderam mais espaço para alguns e que deram prejuízos para os outros. Remexer nesses limites implicava afetar outros limites mais importantes, que deviam ser preservados.

Nessa dinâmica conflitiva, tão importante quanto a observação dos atos que podem deflagrar desentendimentos são os atos observados quando os mesmos não podem ser evitados. Ocorrido um desacordo, o que decorre em seguida é de igual importância. Mais uma vez a política é de uma eloquência exemplar. Nesse momento, ter controle é evitar determinados espaços e assuntos entre antagonistas, administrar as manifestações partidárias de modo que elas não desencadeiem enfrentamentos mais diretos, mais violentos. Mesmo que não se evite a divisão comumente vivenciada durante o período, a maneira como as dissensões (mais ou menos provocativas) são vividas é fundamental para sua continuidade ou descontinuidade em outros tempos. Quanto menor a intensidade da variação criada pelo partidarismo, maior a possibilidade de converter o intervalo sob os moldes de outras segmentações, que ao comparadas à divisão dos lados, podem ser menos perniciosas (porque são menos intensas em termos de desacordos ou porque não se atualizam em dissensão).

Observar a duração e a intensidade do desentendimento não é uma questão que se coloca apenas à variação mais dos tempos políticos. Se nesse contexto, o controle é uma medida que se efetua através da administração das manifestações partidárias, em situações mais cotidianas o procedimento frequentemente diz respeito ao mapeamento dos distanciamentos, indiferenças e outros indícios de tensões. Ter controle geralmente refere-se 
às tentativas de modular esses distanciamentos. $\mathrm{O}$ ato de Liduína em levar o queijo até sua irmã também fala um pouco sobre isso: mesmo não sabendo se a ausência da irmã à sua casa prenunciava ou não a dissensão instalada, Liduína não deixou que sua dúvida sugerisse indiferença ao acontecido e tomou a iniciativa da reaproximação.

No entanto, modular distanciamentos nem sempre significa se aproximar da pessoa com quem se desentendeu, como sugere a atitude de Liduína em relação a sua irmã. Uma contenda pode precisar do amaino do tempo para ser dirimida, o qual só é significativo se as partes envolvidas saberem os momentos adequados para se reaproximarem. Enquanto esse momento não acontece (caso realmente venha a acontecer), isso não significa que as pessoas estejam totalmente apartadas umas das outras. Nessas situações, o distanciamento, criado pelo desentendimento, não deixa de pressupor alguma conexão, cuja circunscrição se define ao passo em que se vivem esses acontecimentos.

Janaína e Elvira, nora e sogra, protagonizaram uma discórdia intensa quanto Janaína traiu o filho de Elvira. Após o conhecimento da traição, Elvira dizia que se encontrasse Janaína a espancaria na frente de todos. Mesmo após a separação de Janaína do filho de Elvira, esta não deixou de ameaçar aquela. Janaína se precavia, estando ausente quando a ex-sogra se fazia presente, seja nas rodas de vizinhos (antes frequentadas pelas duas), seja nas casas que tanto uma quanto a outra visitavam. Em algumas situações, não havia como não compartilharem o mesmo espaço, a exemplo das missas na capela, as quais tanto uma quanto a outra nunca deixaram de frequentar.

$\mathrm{Na}$ espreita dos desentendimentos mora a possibilidade de afastamentos mais duradouros, criados pelos deslocamentos ressentidos de filhos, irmão e/ou netos. No caso da contenda entre Elvira e Janaína, o receio de Elvira era ficar longe dos netos, (os filhos da relação de seu filho com Janaína) e podemos imaginar que Janaína não tinha interesse algum em deixar a comunidade, embora esta tenha sido uma possibilidade aventada frente às ameaças de agressão. Ainda que a capela seja um dos raros lugares onde as duas se encontravam, o fato de que, em alguns locais, a presença de uma condicionava a ausência da outra também não deixava de indicar uma forma de convivência. Muitas vezes, esse jogo entre presença e ausência, criado nos espaços onde alguém opta por circular quando o outro está distante, possibilita a permanência no espaço da comunidade. Nessas situações, a distância é a condição da convivência e afirma a existência de uma possível reaproximação, tal como aconteceu entre a nora e a sogra após idas e vindas dos filhos de Janaína (que não deixaram de frequentar a casa da avó), das conversas nas casas das 
vizinhas onde a nora falava sobre o desejo de ficar em paz com a avó dos seus filhos, as mesmas situações que possibilitaram um dia à Elvira indicar que perdoaria Janaína.

\section{Considerações finais: quem muito se evita, convive}

Desentendimentos são acontecimentos que atualizam ao seu próprio modo uma tendência agonística destacada na caracterização de diferentes coletivos (Comerford, 2003; Peristiany e Pitt-Rivers, 1992; Pitt-Rivers, 1977; Campbell, 1974; Black-Michaud, 1975; Gilmore, 1987). A ideia de um convívio marcado por matiz agonístico sugere que as ameaças, perigos e tensões da convivência antes de serem acontecimentos advindos do contato com pessoas estranhas ou de serem criações de situações extraordinárias, afirmam uma condição existencial feita de potências desestabilizadoras. Todos esses estudos destacam uma apreciação coletiva das contendas, que se expressa em encontros e momentos nos quais se protagonizam desafios, ao passo que se criam considerações morais sobre esses mesmos acontecimentos. Nesses diversos contextos etnográficos, os conflitos se notabilizam por mobilizar pessoas, principalmente, por engajar aqueles que partilham a vida cotidiana.

$\mathrm{Na}$ Terceira Margem, a associação entre conflitos e vida cotidiana afirma-se em considerações sobre a necessidade de viverem juntos e próximos e sobre os riscos dessa vivência gregária. As medidas do ter controle, ao indicar as maneiras mais adequadas de conviver uns com os outros, se fazem a partir de um conhecimento partilhado entre os moradores, cujo pressuposto se baseia no fato de que a vida sempre pode se descontrolar. As atualizações possíveis desse matiz agonístico que afeta a experiência margeense ganham força na política e na inveja que desabona o dia-a-dia de cada um, isto sem falar na ambição dos negócios e nas diversas possibilidades de fazer o mal. Tendo em vista a proliferação de afetos malfazejos que habitam as pessoas também se reconhecem as influências mágicas na efetuação da maldade no mundo. ${ }^{11}$

Parte dos riscos que vicejam na familiaridade margeense se expressam ou tomam a forma dos desentendimentos. E é em meio aos desentendimentos que se destaca com mais intensidade um modo de conviver entre parentes e conhecidos, baseado no exercício de diversas modulações para as proximidades e as distâncias. Em várias das situações descritas ao longo desse artigo, vimos que os efeitos das contendas criam novos arranjos relacionais: são situações nas quais o controle se insinua como um modo de relação mais significativo que a diminuição ou a quebra do contato. Nos momentos em que não se pode (ou não se quer) evitar um desentendimento, a atenção das pessoas se volta à gestão desses 
acontecimentos, de modo que os procedimentos nos quais se baseiam o ter controle, antes de exorcizar a ruptura, anunciam outras possibilidades de vinculação entre os antagonistas.

Sendo assim, pode-se dizer que parte desses conflitos diz respeito à disputa dos termos das relações entre as partes. Tendo em vista esse aspecto, a particularidade do desentendimento dá lugar à comparação, à medida que o aproxima de outras dinâmicas conflitivas, a exemplo das intrigas e questões do sertão pernambucano. De acordo com Marques (2002), tão importante quanto o ato que identifica o clímax desses conflitos é o intervalo que se cria a partir dele, momento no qual se apreende um dos fatores mais significativos desses acontecimentos, o qual diz respeito à delimitação e redefinição de vínculos e fronteiras. Nesse contexto, um dos momentos do conflito (a intriga) antes de ser uma rixa perene, marcada por atos de vingança e de reconciliação, é uma "predisposição que define as relações entre as partes" que é própria dos momentos de tensão. ${ }^{12}$

No controle, no seu pressuposto de gestão e contenção, está implícita uma modulação da proximidade e da distância entre aqueles envolvidos direta ou indiretamente na contenda. A especificidade dos casos concretos é o que define o exercício do controle e o mesmo pode ser dito quando tratamos especificamente dessa maneira de relacionar pessoas. De todo modo, os procedimentos implícitos na recomendação (é preciso ter controle) afirmam que os desentendimentos, ao refletirem variações na intimidade, também criam modos de lidar com essas variações, destacando a potência criativa própria a esses intervalos da convivência.

Assim como podemos afirmar que os desentendimentos refletem variações na intimidade, também é fato que nem toda variação traduz conflito, afinal esta não existe apenas como efeito da violação de limites morais. Sempre parciais e em redefinição, as demarcações da intimidade não são problematizadas apenas nas distâncias que os desentendimentos criam, mas também naquelas que se destacam na origem desses acontecimentos, pois eles surgem justamente quando certos limites são desrespeitados.

Desentender-se não deixa de ser uma maneira que a intimidade encontra de afirmar sua existência, ao tangenciar suas próprias demarcações. Marques (2002) chama a atenção para o fato de que as dinâmicas conflitivas descritas em seu trabalho também se atualizam como mecanismo de diferenciação. Podemos ampliar esse entendimento sobre as intrigas e questões, associando-o a outros contextos, bastante diversos do caso pernambucano, mas aproximáveis no que concerne à afirmação da igualdade como valor. No contexto do Alto Paranaíba, os conflitos também não deixam de afirmar a diferenciação constitutiva das 
relações. Assim como não há parentesco quando a distância se faz de forma tão potente, ${ }^{13}$ tampouco há parentesco se não há variação.

Além dos distanciamentos circunstanciais e prescritivos, criados e administrados na dinâmica conflitiva, desentendimentos também afirmam os distanciamentos necessários, aqueles que compõem a variação constitutiva da intimidade, posto que, embora baseada na proximidade, a intimidade pressupõe limites que devem ser respeitados para que ela mesma possa se efetuar. Esses limites são afirmados constantemente não apenas nas divisões e segmentações da política e nas distâncias criadas pelos desentendimentos, na relação consigo mesmo, efetuada no exercício contínuo de se distanciar das próprias paixões (mas não a ponto de esquecer que elas são atuantes), bem como nos marcos da domesticidade tecidos através das práticas de circulação de pessoas, coisas e palavras vividas na localidade.

\footnotetext{
1 Assim me disse um morador, ao afirmar a potencialidade das campanhas eleitorais municipais em dividir e distanciar parentes e conhecidos. Adiante, voltarei a falar da política, destacando suas ressonâncias sob a dinâmica conflitiva observada nesses lugares.
}

2 O trabalho de campo, desenvolvido ao longo desses meses, compreendeu os anos de 2008 a 2009. O presente texto é baseado nesta pesquisa, que também me permitiu elaborar minha tese de doutorado (Dainese, 2011). As discussões aqui realizadas refletem minha atenção aos comentários de Ana Cláudia Marques, durante sua arguição na ocasião da defesa desta tese. Aproveito para agradecer não apenas à Ana Cláudia, mas também ao John Comerford, ao André Dumans Guedes e à Carmen Andriolli pela leitura deste texto e por seus comentários. Feita essas considerações, não é demais afirmar que sou a única responsável pelos equívocos e incompreensões que possam constar neste trabalho.

3 A fim de preservar as pessoas com quem trabalhei, optei por nomes fictícios tanto para as localidades quanto para as pessoas, excetuando a designação regional e estadual (Alto Paranaíba - Minas Gerais).

${ }^{4}$ Em outros trabalhos (Dainese, 2011; 2015), descrevo mais detalhadamente a importância do movimento entre os moradores dessa localidade, as práticas que o efetuam assim como a transformação relacional criada a partir das andanças e chegadas.

5 Como notou Comerford (2003), provocaçães não são acontecimentos óbvios, à medida que sua ocorrência frequentemente é alvo de discussão. Há margem para dúvida sobre algo ter sido ou não provocado, margem esta que também é parte do cálculo de um jogo envolvente. Desse modo, provocações não redundam apenas em enfrentamentos acintosos, pois a incerteza sobre uma situação ou gesto ter sido ou não provocado atrai atenções de modo a criar um clima que entretêm a ponto de desencorajar o melindre. No entanto, assim como há situações nas quais a provocação ficou no ar (sublimando-se em hesitações que acovardam a contenda), também há situações que o cálculo da provocação não deixa margem para a incerteza, de sorte que os envolvidos reconhecem sua potencialidade mais imperativa. $\mathrm{Na}$ sequência do texto, descrevo como a política é um desses momentos nos quais provocar é afirmação do desrespeitar.

${ }^{6} \mathrm{O}$ partidarismo é referência para a polarização especificamente criada pelas campanhas eleitorais municipais, quando os eleitores se dividem em PMDB e DEM. Nesse sentido, diz respeito menos às siglas (e/ou a um programa ideológico representado por elas) e mais a um princípio divisor. Muitas vezes não se fala em partido, mas sim em lados: o partidarismo traduz uma dinâmica que é, sobretudo, localizar-se em um dos dois 
lados, que podem ser nomeados por siglas mais atuais, a exemplo das citadas acima, mas que podem ser tranquilamente substituídas por UDN e PSD. A referência aos partidos de campanhas tão antigas, tal como supõe a menção aos udenistas e pessedistas, reforça o entendimento de que não importa o nome que se dê aos lados: sua existência é criação de uma dinâmica que independe de programas ideológicos, mas que não prescinde da divisão.

7 Mesmo que a dinâmica eleitoral redefina as fronteiras sociais, de modo a evitar que as manifestações partidárias se reproduzam de forma menos intensa (algo que se nota nos bares que deixam de ser frequentados porque lá se tornou o reduto do lado antagonista, dos assuntos que não se conversam porque ali estão presentes pessoas de lados opostos), a transgressão não deixa de ser recorrente. Sobre política e redefinição de limites e fronteiras, ver Guebbel (1996) e Palmeira e Heredia (1995; 1997).

8 A sazonalidade afirmada na expressão “tempo da política” remete à excepcionalidade que é, sobretudo, criação/transformação. Sob inspiração agostiniana, Palmeira (2001) argumenta que a organização da vida social em tempos (tal como equacionada por determinados coletivos sociais: tempo da política, tempo de festa, tempo de colheita) implica outro ritmo para as atividades e para os comportamentos. "Trata-se de criar um tempo próprio para o desempenho de determinadas atividades consideradas importantes pela sociedade" (Palmeira, 2001: 173). O fato de, em certas situações, o termo política seja sinônimo para a expressão tempo da política significa que esta é o próprio tempo, ou seja, é o momento de criação por excelência, sentido que é próprio ao termo que lhe acompanha, mas que, em determinados contextos, a ela está subsumido. Entre os margeenses, essa concepção é sugerida pelo entendimento de que "na política há muito movimento", expressão que associa a campanha eleitoral municipal a um momento de maior circulação de pessoas, de diversificação de acontecimentos, de transformação dos espaços, de irrupção da paixão. É uma atividade que intensifica determinados acontecimentos: seu movimento é aceleração/transformação da vida.

9 No contexto margeense, a sazonalidade, ao traduzir a potencialização de acontecimentos cotidianos, também traduz uma tendência coletiva em gerir a dissensão, afirmando ao seu próprio modo, um princípio geral da circunscrição "tempo da política”, o qual supõe a delimitação para a ocorrência mais autorizada dos conflitos. De acordo com Palmeira e Heredia (2010): “(...) o tempo da política, a par de circunscrever conflitos que tendem a ocorrer na regulação das relações entre unidades políticas e administrativas, é crítico na definição e redefinição dos pertencimentos sociais. (...) Dito de outro modo, o "tempo da política" permite a resolução de conflitos não resolvidos ou não resolvíveis no fluxo das interações cotidianas ou, pelo menos, a rearrumação do "passivo" de conflitos acumulados sob a égide da união" (2010:168).

${ }^{10}$ Em localidades como Terceira Margem, o catolicismo é religião professada e experiência importante aos moradores que a ela se dedicam, seja na organização de festas e novenas na capela durante os finais de semana ou de rezas de terços e orações nos dias de semana. Nesse cotidiano, orações como Ave Maria e Pai Nosso podem ser feitas nas casas ou na capela, em grupo ou individualmente. Fazer o sinal da cruz ao passar pela capela (ou à frente de outras edificações católicas) é mais um desses atos que participam do exercício de rezar.

11 Um olhar mais atento para as dinâmicas que mexem com a vida coletiva margeense a partir da maldade e de outras experiências malfazejas pode ser encontrado em Dainese (2011)

12 "Nas disputas a que tenho me referido, talvez importe mais o que se passa nos intervalos do que nos atos propriamente ditos, quando os atores e a plateia, encontrando-se nos bastidores, acabam por decidir, mesmo não intencionalmente, os rumos do espetáculo a ser visto por todos. Todos juntos interferirão na situação dos rivais não somente entre si, mas no seio de seus pares, reverberando nas suas outras relações. Assim, para compensar um dano sofrido, o ressarcimento material da cerca, do pasto, da terra pode ser insuficiente. Mediante as disputas, acrescentam-se novos traços na própria imagem, voltada para foram, porque estamos em um ambiente em que, de modo muito agudamente sentido o outro é a medida de si mesmo." (Marques, 2002: 54).

${ }^{13}$ Este é o risco implícito à política, pois sua ocorrência, embora crie seus próprios mecanismos de gestão da divisão e das segmentações, não deixa de traduzir a possibilidade do fim: na politica, o parentesco acaba. 


\section{Referências bibliográficas}

BLACK-MiCHAUD, Jacob

1975 Cohesive Force. Fend in the Mediterranean and the Middle East. Nova York, St. Martine's Press.

CAMPBELL, John

1974 Honour, Family and Patronage. Oxford, Oxford University Press.

COMERFORD, John

2003 Como uma família: sociabilidade, territórios de parentesco e sindicalismo rural. Rio de Janeiro, Relume-Dumará.

DAINESE, Graziele

2011 Chegar ao cerrado mineiro: hospitalidade, politica e paixões. Rio de Janeiro, tese, Museu Nacional/UfrJ, 341 pp.

2015 "Movimento e animação das festas, visitas, andanças e chegadas". Artigo enviado para publicação ao periódico Mana, Museu Nacional/UfrJ.

Figureldi, Monica Fernanda

2007 Decompondo registros: conflitos de terra em Pernambuco. Rio de Janeiro, dissertação, Museu Nacional/UfRJ, 136 pp.

2011 Familias, escravidão, luta: histórias contadas de uma antiga fazenda. Rio de Janeiro, tese, Museu Nacional/UfrJ, 270 pp.

Foucault, Michel

1984 História da Sexualidade ii. O uso dos prazeres. Rio de Janeiro, Edições Graal.

1985 História da Sexualidade iii. O cuidado de si. Rio de Janeiro, Edições Graal.

GILMORE, David

1987 Agression and Community. Paradoxes of Andalusian Culture. New Haven, Yale Universtiy Press.

GuebBel, Claudia

1996 "O bar de Tita: política e redes sociais". In Palmeira, Moacir e Goldman, Marcio. (orgs.). Antropologia, voto e representação política. Rio de Janeiro, Contracapa, pp. $73-84$.

LATOUR, Bruno

2002 Reflexão sobre o culto moderno dos deuses fe(i)tiches. Bauru, Edusc. 
MAYBLIN, Maya

2010 Gender, catholicism and morality in Brazil. Virtuous busbands, powerful wives.

Palgrave, Macmillan.

MARQues, Ana Cláudia

2002 Intrigas e Questões: Vingança de família e tramas sociais no sertão de Pernambuco. Rio de Janeiro, Relume-Dumará.

PALMEIRA, Moacir

2001 "Política e Tempo: nota exploratória". In PeIRAno, Marisa (org.). O dito e o feito: ensaio de antropologia dos rituais. Rio de Janeiro, Relume-Dumará, pp. 171-177.

Palmeira, Moacir e Heredia, Beatriz

1995 “Os comícios e a política de facções”. Anuário Antropológico, 94: 31-93.

2010 "Política Ambígua". In Política Ambígua. Rio de Janeiro, Relume-

Dumará, pp. 167-186.

Peristiany, J. G. e PitT-Rivers, Julian

1992 Honour and Grace in Anthropology. Cambridge, Cambridge University Press.

PITT-RIVERS, Julian

1977 The People of the Sierra. Chicago, The University of Chicago Press. 


\section{Misunderstandings between relatives: variations of intimacy}

ABSTRACT: The possibility of misunderstandings (desentendimentos) emergence among the residents of Terceira Margem (community located in the state of Minas Gerais) makes people express and values a knowledge concerning the relationships. In this sense it highlights the valuation of a self-discipline marked by attitudes and behaviors contention and the constant modulation between proximity and distance in the contact with each other. So in this paper I will present how the explicit and implicit tensions are experienced in this research context, considering the dialogue with the perspective of analysis whose premise is to approach conflicts in the threads which they are constitutive, paying attention to the relational effects created by these events. The attention to the way the conflict is experienced among the inhabitants of Terceira Margem reveals a relational dynamics which is not necessarily unique to a context and / or situation, because its principles and processes are related both to the instabilities as the stabilities of existence.

KEYWORDS: Conflict, Politics, Subjectivity, Differentiation.

Recebido em janeiro de 2013. Aceito em abril de 2015. 